\title{
IMPLICATIONS OF PLUME DISCHARGE FOR TIDAL CHANNELS MORPHODYNAMICS: A COUPLED ONSHORE AND OFFSHORE SYSTEM
}

\author{
Jiménez-Robles, A.M. ${ }^{1}$, Lanzoni, S. $^{2}$, Ortega-Sánchez, M. ${ }^{1}$
}

\begin{abstract}
This contribution investigates the morphodynamic equilibrium of a funnel-shaped, well-mixed tidal channel taking into account the existing dynamical coupling between the tidal channel itself and the related offshore sediment-laden plume. We use a quasi two-dimensional numerical model that resolves the fully nonlinear unsteady shallow water, sediment bed load transport and suspended sediment advection-diffusion equations along with the Exner equation for the bathymetric changes. We close this model by including a dynamic boundary condition at the channel mouth that transfers the offshore plume sediment concentration to the channel dynamics. This model reveals that the offshore plume reduces the timescales to reach equilibrium of the channel and plays a crucial role on shaping it. At equilibrium, the non-plume influence case attains a quasi-linear profile of constant slope in the seaward part. However, the bottom profile in the case that includes the offshore plume tends to increase the concavity of the bottom profile, reducing the final channel mouth depth. Finally, numerical results suggest that the plume characteristics are altered as a consequence of tidal channel evolution.

Keywords: tidal channel morphodynamics; offshore plume; numerical modelling
\end{abstract}

\section{INTRODUCTION}

We focus this work on the case of a well-mixed, tide-dominated estuary connected to its offshore plume in which river and waves processes are merely subordinates or neglected. In recent years, different works have been developed to tackle the issue of the the possible existence of a long-term longitudinal equilibrium of tidal channels. For a detailed discussion of the concept of morphodynamic equilibrium in estuarine ambients the reader is referred to Zhou et al. (2016). Tidal channel morphodynamics is dictated by asymmetries in surface elevations and tidal currents that lead to a net sediment flux directed landward within a tidal cycle (De Swart and Zimmerman, 2009). Laboratory experiments (Tambroni et al., 2005), analytical methods (Schuttelaars and Swart, 1996, 2000; Prandle, 2003; Seminara et al., 2010) and numerical techniques (Lanzoni and Seminara, 2002; Hibma et al., 2003; Yu et al., 2012; Bolla Pittaluga et al., 2015) found that, starting from an arbitrary initial bottom profile, the system asymptotically tends to a long-term morphodynamics equilibrium state with a nearly constant value of the maximum flood/ebb speed. This dynamic equilibrium state is characterized by a vanishing net (tidally-averaged) transport in the entire embayment that results in a shoaling bed with water depths decreasing from the inlet to an emerging shore landward.

In the above-mentioned numerical works, onshore tidal estuaries and offshore plumes are not treated as a whole. They prescribed a fixed boundary condition at the estuary mouth by which during the ebb phase the sediment load at the inlet simply exits the estuary whereas during the flood phase an entering sediment load in equilibrium with the local instantaneous hydrodynamics is prescribed. On the other hand, works focused on offshore plume processes are carried out in a framework of no connectivity with the issuing channel. Related fluid dynamics and sediment patterns on the oceanic region are based on a boundary condition at the channel mouth (Wright, 1977; Özsoy, 1986; Wang, 1984; Leonardi et al., 2013, 2014; Fagherazzi et al., 2015; Jiménez-Robles et al., 2016).

However, Stommel and Former (1952) first suggested the importance of the exchange at the boundary between a tidal channel and the ocean to regulate the flushing of sediment constituents and in controlling conditions within a tidal embayment as a whole. Hence, the connectivity between the onshore and offshore systems must be a task to be addressed when analyzing tidal channels morphodynamics.

The issue that we address in this contribution concerns the possible existence of a long-term longitudinal equilibrium profile in tide-dominated, well-mixed estuaries linked to their offshore discharge plume. The problem is tackled by adopting a quasi 2-D model of a coupled tidal channel and offshore plume system. We use the one-dimensional shallow water continuity and momentum equations linked to the Exner equation for the bottom evolution in the tidal channel. These equations are dinamically coupled to the flow and sediment patterns in the offshore region by means of a sufficiently simple analytical model of plume hydrodynamics that reduces drastically the computational effort. In the near field, during the ebb-phase tidal plumes behave as a bounded, sediment-laden, turbulent jet (Rajaratnam, 1976; Joshi, 1982; Ortega-Sánchez et al., 2003; Jiménez-Robles et al., 2016). The approximate equations for the jet flow and sediment patterns

\footnotetext{
${ }^{1}$ Environmental Fluid Dynamics Group, Andalusian Institute for Earth System Research, University of Granada, Spain

${ }^{2}$ Department of Civil, Architectural and Environmental Engineering, University of Padua, Italy
} 
were derived by Özsoy and Ünlüata (1982) and Özsoy (1986) respectively. On the other hand, the flood flow in the near inlet region is modelled as a two-dimensional, plane, irrotational plane sink flow (Blondeaux et al., 1982). The resulting system is closed by the sediment flux transported as bed and suspended load through an empirical transport capacity formulation and the advection-diffusion equation respectively. In this contribution we are taking into account the phase lag between local hydrodynamic conditions and sediment fluxes.

Despite important advances in previous works, with this model we wish to answer some unknowns about the morphodynamics of 'short' tidal channels typically observed in coastal lagoons and wetlands, and related river plumes: Could the offshore plume alter the this scenario? If so, how does offshore dynamics influence the sediment supply of a tidal channel and the consequent equilibrium configuration? And viceversa, how does the tidal channel evolutions modifies the plume dynamics?

\section{FORMULATION OF THE PROBLEM Model Geometry}

A simplified geometry is used to define the characteristic funnel-shaped planimetric configuration of a tide-dominated estuary (Lanzoni and Seminara, 1998). Let us considerer a tidal channel of length $L_{e}$ whose width $b$ decreases exponentially with distance inland:

$$
b=b_{0} \exp \left(-\frac{x}{L_{b}}\right),
$$

where $b_{0}=b_{\text {mouth }}$ is the channel width at the channel mouth, $x$ is the longitudinal coordinate with origin at the channel mouth and pointing landward, and $L_{b}$ denotes the convergence length. The channel cross-section is assumed to be rectangular with a local depth defined by $d=h-\eta$, where $h$ is the water surface elevation and $\eta$ is the laterally averaged elevation of the channel bottom, both relative to a reference level (see Figure 1). As a first approximation, the channel width is assumed to be flanked by non-erodible banks and we ignore the possible presence of adjacent tidal flats. The oceanic receiving basin will be characterized by a flat bottom with bathymetric lines parallel to the coast.

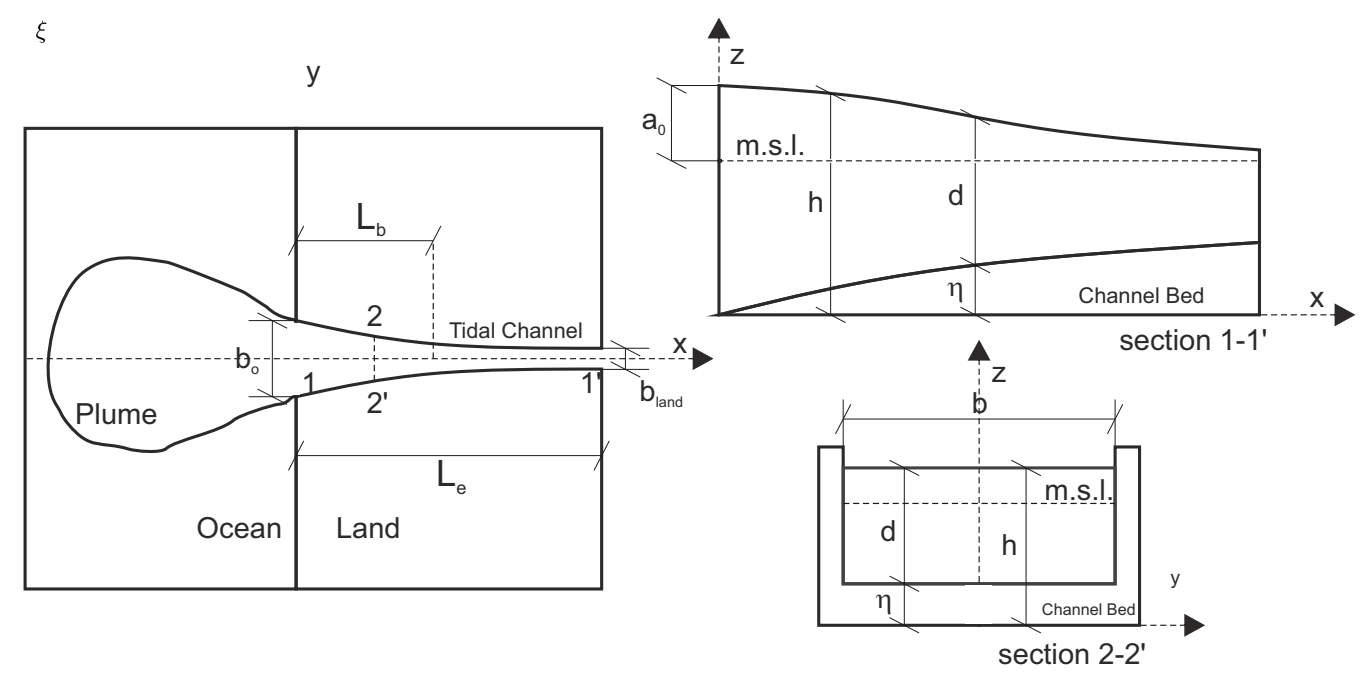

Figure 1: Sketch of a tidal channel-offshore plume system and basic notation.

\section{Hydrodynamic Model}

The one-dimensional partial differential equations governing the unsteady water flow in the tidal channel are the classical shallow water equations of mass and momentum conservation:

$$
b \frac{\partial d}{\partial t}+\frac{b u d}{\partial x}=0
$$




$$
\frac{\partial u}{\partial t}+u \frac{\partial u}{\partial x}+g \frac{\partial h}{\partial x}+\frac{u|u|}{C^{2} d}=0
$$

where $t$ denotes time, $u$ is the local depth-averaged velocity, $g$ is gravity, and $C$ is flow conductance estimated on the basis of bed material and bed form characteristics (van Rijn, 1993).

Two boundary conditions are required by the previous system. At the estuary mouth the system the water motion is forced by a sea level oscillation characterized by a purely semi-diurnal M2 tide of amplitude $a_{0}$. At the landward boundary the river discharge is supposed to be negligible.

To complete the model hydrodynamics, in the offshore flow motion two well-differentiated phases with a particular flow treatment are considered in the present framework: the ebb and flood offshore flow field.

For the ebb-phase, jet theory has been extensively used to describe processes experienced by water discharges into resting reservoirs during the ebb-phase (Ortega-Sánchez et al., 2008). Ideally, these flows can be divided into two different zones: (1) a zone of flow establishment (ZOFE), located in the vicinity of the outlet and governed by a triangular inviscid core; and (2) a zone of established flow (ZOEF), where lateral shear turbulence reaches the jet axis and centerline velocity starts to decrease. Özsoy and Ünlüata (1982) derived an analytical solution for a stationary turbulent jet hydrodynamics that can be characterized by the solutions of the velocity field $u_{j e t}(x, y)$ and of the jet half-width $b_{j e t}(x)$.

Regarding the flood-phase flow, it is modeled as 2-D inviscid, plane and irrotational sink flow by assuming the bed to be fixed in time using the potential flow theory (Tambroni and Seminara, 2006). Potential flow theory leads to the analytic determination of flow characteristics based on a transformation between the physical plane and the complex potential plane using the Schwarz-Christoffel transformation technnique (Vallentine, 2013).

\section{Morphodynamic Model}

In this work we consider that the only source of sediment, which will be composed of an uniform noncohesive sediment with grain diameter $d_{s}$ derives from the tidal channel bottom. Hence, hydrodynamics computations in the continental shelf will be carried out assuming a fixed flat shelf of constant slope. The morphodynamic evolution of the tidal channel bottom is governed by the Exner for sediment continuity (Paola and Voller, 2005):

$$
(1-p) b \frac{\partial \eta}{\partial t}+\frac{\partial\left(b q_{b}\right)}{\partial x}=D_{e}-E_{r}
$$

where $A=b * d$ is the channel cross-sectional area, $p$ is sediment porosity, $q_{b}$ is the bedload transport rate per unit width, and $D_{e}$ and $E_{r}$ are the deposition and erosion rates of suspended sediment per unit channel length. The bedload sediment transport in the tidal channel is here computed employing the MeyerPeter and Müller (1948) equilibrium formula. This expression, empirical in nature, enjoys wide use in nearshore sediment applications (Soulsby, 1997). It reads:

$$
q_{b}=8\left(\theta-\theta_{c r}\right)^{3 / 2}\left(\Delta g d_{s}^{3}\right)^{1 / 2}
$$

where $\Delta$ is the submerged specific density of the sediment, $\theta=\left(u_{*}^{2} /\left(\Delta g d_{s}\right)\right)$ is the Shield stress with $u_{*}$ being the bed-shear velocity, and $\theta_{c r}$ is the threshold value of the Shield stress for beginning of bed load transport. Besides, we compute the suspended sediment concentration inside the tidal channel and during the flood-phase in the offshore region through a one dimensional advection-diffusion equation:

$$
\frac{\partial c}{\partial t}+\frac{\partial u c}{\partial x}=\frac{E_{r}-D_{e}}{A}+\frac{1}{A} \frac{\partial}{\partial x}\left(k_{x} A \frac{\partial c}{\partial x}\right),
$$

where $c$ is the cross-sectionally averaged concentration, and $k_{x}$ is a longitudinal diffusivity coefficient. The instantaneous rate at which sand is picked up is given in terms of a pickup function $E_{\text {ent }}$ (van Rijn, 1984b; Chaudhry, 2007):

$$
E_{r}=E_{\text {ent }} w_{s} b
$$

where $w_{s}$ is the fall velocity of non-spherical sediment particles (van Rijn, 1984a). Finally, Winterwerp (2007) suggested that the deposition rate can be represented by the settling flux: 


$$
D_{e}=c w_{s} b
$$

As in the hydrodynamic problem, the plume sediment concentration in ebb-tidal jets is computed using the quasi-stationary solution of the jet theory Özsoy (1986). The morphodynamic problem is closed by imposing that the instantaneous bedload flux and sediment concentration at the seaward end of the receiving basin $(x \rightarrow-\infty)$ must vanish. Regarding the advection-diffusion equation in the channel, a variable boundary condition is employed. It is applied at $x=L_{e}$ during the ebb-phase and at $x=0$ during the flood phase. This boundary condition allows the transference of the sediment concentration existing in the basin at $x=0$ that is entering into the channel during the flood phase.

\section{Numerical Scheme}

The differential system for the liquid phase (equations (2) and (3)) and for the solid phase (equations (4) and (6) is resolved through the MacCormack explicit finite-difference method. It is a shock-capturing, fractional-step predictor-corrector method that achieves second order accuracy in space and time, and is numerically stable if the Courant-Friedrichs-Lewy condition is fulfilled.

\section{RESULTS}

Influence of Offshore Plume on Tidal Channel Evolution

Figure 2 compares the long-term bottom equilibrium profiles for two cases: without and under the plume dynamics influence. The first case is achieved by assuming that the suspended sediments of the plume settle immediately after the end of the ebb-phase. On the other hand, the only source of sediment will be the material coming from the tidal channel bottom, i.e., erosion in the offshore region will be ignored.
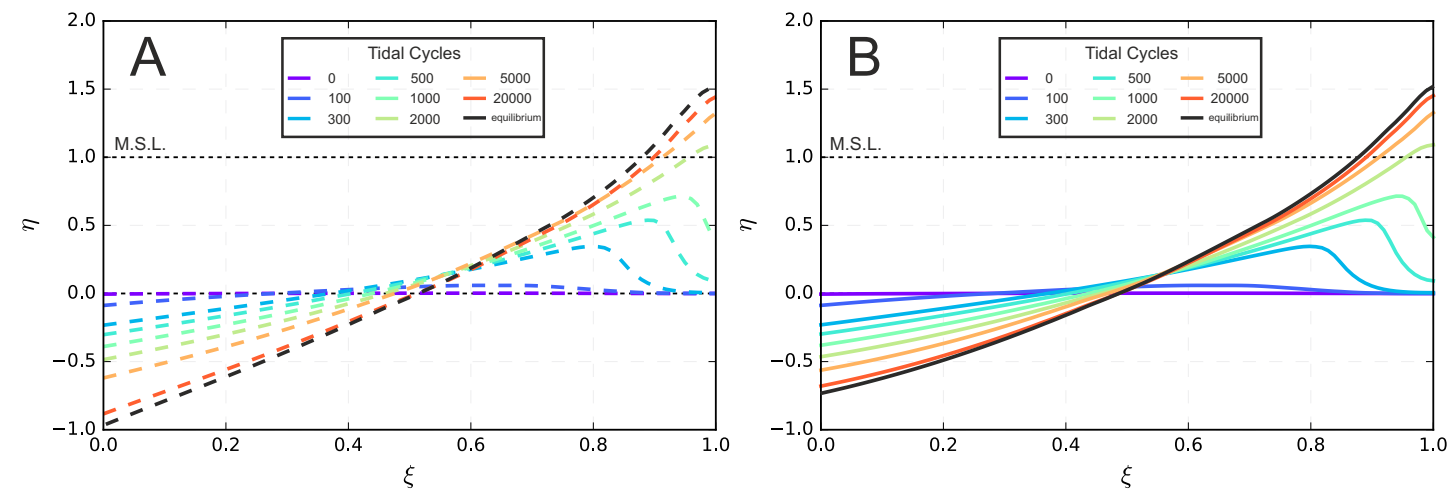

Figure 2: Long-term evolution of the bottom profile of a short convergent estuary $\left(L_{e}=30 \mathbf{~ k m}, L_{b}=25 \mathbf{k m}\right.$, $a_{0}=\mathbf{2 . 2} \mathbf{m}, d_{s}=200 \mu \mathrm{m}$; initial condition: $d_{0}=6 \mathrm{~m}$ ) at different tidal cycles during the simulation of a tidal channel (a) without and (b) with the influence of the offshore sediment laden plume. The bottom elevation at each cross section has been scaled with the initially uniform depth, while the estuary length has been used to scale the longitudinal coordinate $(\xi)$. The horizontal dotted line represents the location of the mean sea level.

Figure 2 shows that both cases follow an identical transient process during the first stages of their evolution. Starting from an initial horizontal bed profile, a sediment front resulting from the scoured sediments at the seaward portion of the channel aggrades and migrates toward the inner portion, generating a shoaling bed profile. Later, the front tends to be completely reflected, eventually leading to bed emersion and the formation of a shore in the landward portion of the tidal channel. Nevertheless, once the sediment front reaches the landward boundary, the trend followed by both cases differs substantially in the seaward portion of the tidal channel. Whereas the non-plume influence case attains a quasi-linear profile of constant slope (Figure 2 (a)), similar to the one reported by Lanzoni and Seminara (2002) and Todeschini et al. (2008), the bottom profile in the case that includes the coupling of plume and tidal channel tends to increase the concavity of the bottom profile, reducing the final channel mouth depth (Figure 2 (b)).

It is important to note that the long-term simulations of bathymetric changes in a tidal embayment shown in Figure 2 finally reach a stable morphologic pattern characterized by an upward concavity and by 
a well-defined depth at the inlet section. Based on the Exner equation (4), a tidal channel is in an strict morphodynamic equilibrium provided the gradient of the bed load sediment transport equals the balance of erosion and sedimentations of suspended sediment. This is a highly severe requirement for defining a feasible equilibrium state in a such dynamic system: the equilibrium must be considered as a weakly dynamic state. It makes us to explore a less-restrictive equilibrium configuration based on the root-meansquare $(\mathrm{rms})$ of the bed level changes integrated all along the estuary between successive cycles. It reveals a reduction in the rate of morphodynamic activity over time and relatively stable morphologic patterns evolve (Figure 3). It allows us to establish a quasi-equilibrium configuration by imposing a threshold value for the $r m s$ variation below which equilibrium is assumed if this value is not exceeded during a given number of years. The rms value for the year $k$ is given by

$$
r m s(k)=\left[\frac{1}{N} \sum_{i=1}^{N}\left(\eta_{i}^{k}-\eta_{i}^{k-1}\right)^{2}\right]^{1 / 2},
$$

where $N$ is the number of point of the bottom profile. In this work, a $r m s$ threshold value equal to 5 $\cdot 10^{-3} \mathrm{~m}$ and a duration of five years are imposed. As shown in Figure 3, the initiation of channel evolution causes considerable bathymetric changes, resulting in large rms-deviation values. Indeed, at the first year it reaches a peak value of $1.6 \mathrm{~m}$ for both cases, with and without the influence of the offshore plume. From this peak, both curves follow a negative-exponential trend characterized by a decreasing rate of the morphodynamic activity. Two regions are well-defined in both curves. An initial region where the overall morphological evolution occurs at a slower pace, during which the sediment front migrates landward and is eventually completely reflected. This region finishes with a "morphological-readjustment" peak, that coincides with the moment in which the beach emerges above the high water level and after which the $r m s$-deviation follows an asymptotic trend of weak morphodynamic activity. An important feature shown in Figure 3 is the remarkable increase of the transient period of morphodynamic activity before reaching the imposed condition for equilibrium by the case without offshore-plume ( $\approx 97$ years) with respect to the case with the offshore-plume $(\approx 41$ years). It reveals the net sediment exchange processes between the plume and the tidal channel as a key factor that speeds up the development of stable channel patterns.

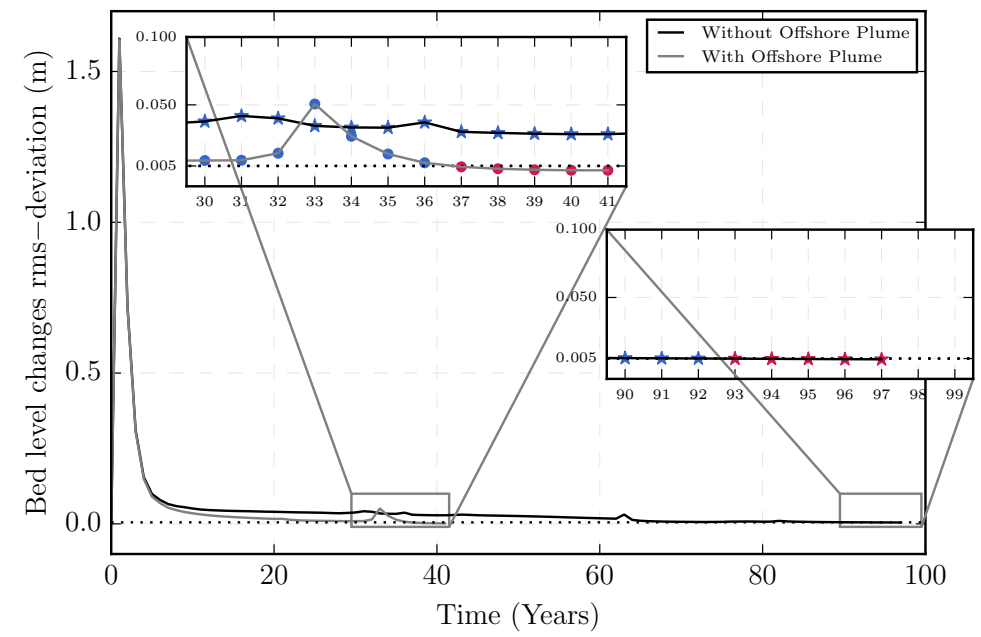

Figure 3: Root-mean-square of the bed level changes between successive years computed over all the channel points as a function of time for two cases: without and under the influence of the offshore plume. Blue symbols represent values above the threshold of $5 \cdot 10^{-3} \mathrm{~m}$, while red symbols are located below this value.

\section{Influence of Tidal Channel Evolution on Offshore Plume Dynamics}

The along-plume normalized centerline velocity (Figure 4 (a)), plume half width (Figure 4 (b)) and plume centerline sediment concentration (Figure 4 (c)) can be readily evaluated for different stages of the tidal channel evolution, i.e., when the channel is at the beginning of the simulation and when the channel 
reaches a condition of dynamic equilibrium, by using the classic theoretical model for determining plume properties presented previously.
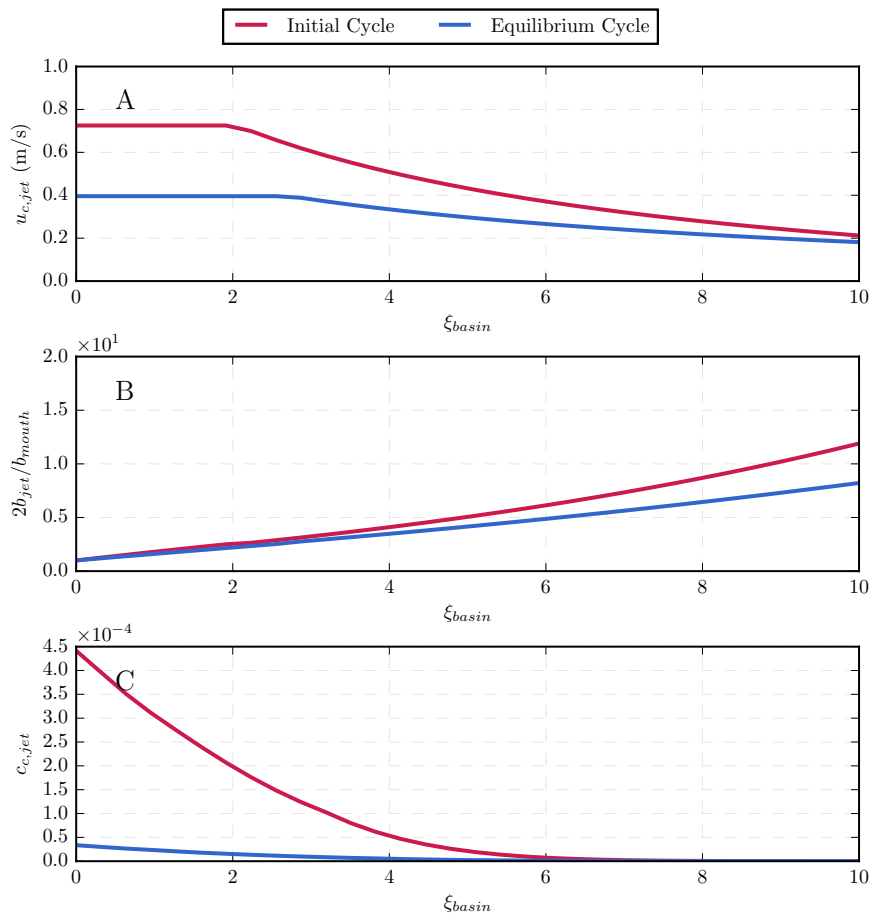

Figure 4: Plume characteristics at different stages of tidal channel evolution: at the beginning of the simulation (red lines) and at equilibrium(blue lines)). (a) Plume axis velocity, (b) normalized plume half-width normalized by the tidal channel mouth width, and (c) plume axis sediment concentration are shown. The channel mouth width has been used to scale the longitudinal coordinate $\left(\xi_{\text {basin }}\right)$

The evolution toward an equilibrium configuration of the tidal channel is achieved by reducing the asymmetry between ebb and flood duration and velocities (Lanzoni and Seminara, 2002). At the beginning of the simulation, the strong velocity peaks during the ebb-phase give rise to higher velocities on the continental shelf than the velocity peaks of the tidal channel once it achieves the equilibrium. In this final state both the velocity asymmetries and the intensity of the velocities during the tidal cycle decrease considerably, which is reflected in the less energetic velocity field existing in the offshore plume located in the continental shelf (Figure 4 (a)). A second consequence of the tidal evolution on the velocity field of the offshore plume is the increase of the zone of flow establishment length (plume or jet core) where centerline velocity can be assumed constant. As observed in Figure 4 (a), the zone of flow establishment is enlarged at the end of the simulation. Because the frictional term is inversely proportional to the water depth, the observed erosive processes at the channel mouth will reduce the friction experienced by the plume along its axis. Consequently, the reduction of the friction experienced by the plume once it debouches into the continental shelf prevails over the decrease in the channel velocities and an increase in the plume core length arises.

A direct consequence of the vanishing of velocity asymmetries, the reduction of velocity peaks, and of the increase of the channel depth is that the plume narrows during the channel evolution (Figure 4 (b)). The cause for this plume contraction in the equilibrium state is related to mass conservation and, mainly, the variation of frictional effects. The frictional parameter $\mu$ combines a number of effects, such that when friction is large or the inlet width is large compared to depth, the jet merely explodes as it faces the bottom resistance and loses its momentum (Özsoy and Ünlüata, 1982). While at the beginning of the simulation these three effects will be acting in the same way to lead to the expansion of the plume, at equilibrium the increase of water depth will reduce the rate of plume expansion. Thus, as depicted from Figure 4 (a) and Figure 4 (b) it is shown that, under general circumstances, the effect of increasing tidal channel mouth 
depth during its morphodynamic evolution is to counteract the effects of the continental shelf friction and the lateral entrainment of ambient nonturbulent water of the ocean into the plume. Consequently, narrower plumes arise during the equilibrium processes experienced by a tidal channel due to the vertical expansion experienced by them.

A third direct consequence of the tidal channel evolution is the considerable decrease of the centerline concentration of sediment existing on the offshore plume once the tidal channel reaches the equilibrium (Figure $4(\mathrm{c})$ ). A comparison between the exiting sediment concentration (values of $c_{c, j e t}$ at $\xi_{\text {basin }}=0$ ) both at the beginning of the simulation and at the equilibrium state reveals that the gradient between erosive $\left(E_{r}\right)$ and deposition $\left(D_{e}\right)$ reduces considerably inside the tidal channel. Hence, the reduction of sediment to be exported linked to a less energetic velocity field that makes the the transported material speed up its deposition give rise to a drastic fall in the concentration field exiting in the offshore region encompassed by the plume.

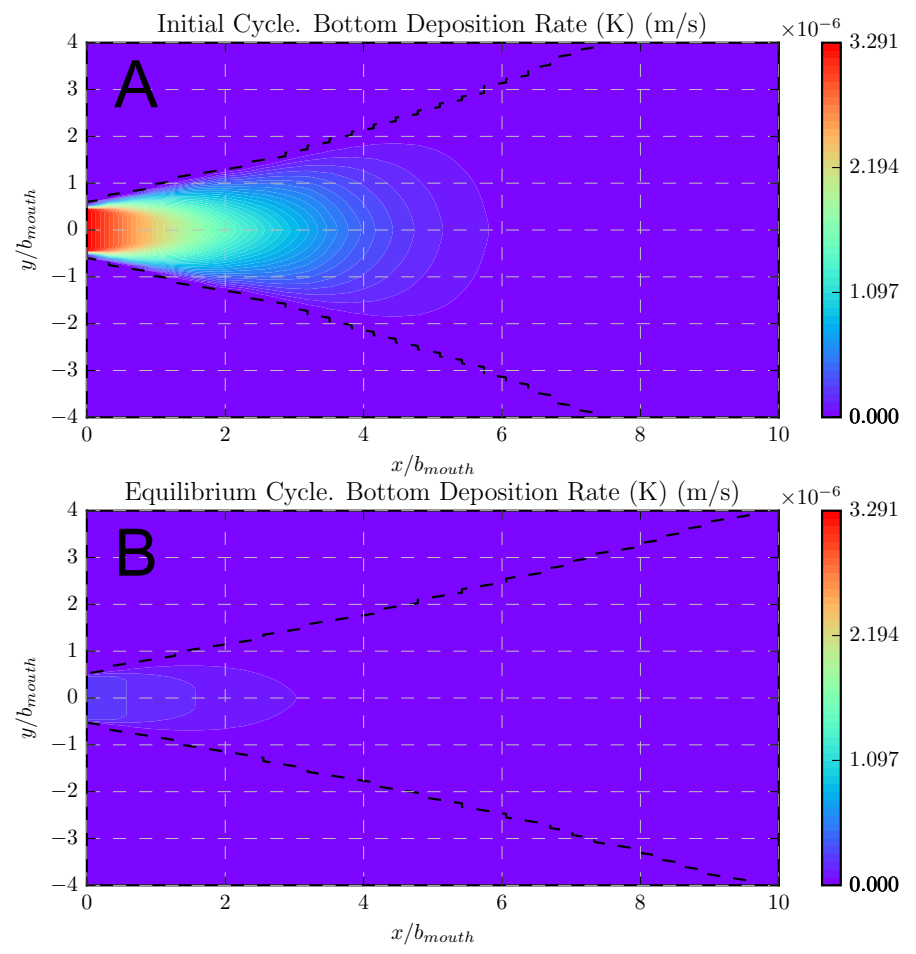

Figure 5: Solutions for bottom deposition rate fields of erosion in the offshore region $(\mathrm{K})$ at different stages of tidal channel evolution: (a) at the beginning of the simulation and (b) at equilibrium. Black dashed lines represent the width of the plume.

Given the solutions for velocity and concentration along the plume centerline, the amount of material deposited or eroded,per unit area of the continental shelf and unit time $(K)$, can be obtained by considering the source and sink sources (Özsoy, 1986). Figure 5 reveals that the trend in erosion/deposition patterns in the continental shelf shows a high dependence on the equilibrium stage of the tidal channel. Herein we introduce conceptual considerations on processes allowing the formation of mouth bars. Recalling that the material of the continental shelf can not be entrained into suspension, no negative values appear in Figure 5. An initial deposition region of high intensity next to the channel mouth and an important lateral diffusion of sediments appears at the beginning of the simulation due to the larger quantity of eroded material close to the tidal channel outlet (Figure 5 (a)). This feature of the deposition function indicates the possible formation of a mouth bar which thickness decreases seaward and toward the plume margins. On the other hand, the deposition rates at the continental shelf reduce sharply, both in extension and, mainly, in an order of magnitude its intensity (Figure 5 (b)). 


\section{CONCLUDING REMARKS}

This work analyzes the long-term morphological evolution of a tide-dominated estuary by including the influence that the offshore discharge plume has over the evolution of the coupled system. Previous works focused on the long-term evolution of tidal channels imposed a fixed boundary condition at the tidal mouth (i.e. (Lanzoni and Seminara, 2002; Todeschini et al., 2008; Yu et al., 2012; Bolla Pittaluga et al., 2015). During the flood phase they prescribed a sediment load in equilibrium with the local hydrodynamics at this boundary, whereas during the ebb phase the sediment load computed at the inlet is simply assumed to leave the estuary. The main novelty of the present contribution is the inclusion of a link between the hydrodynamics and morphodynamics that occur both in the tidal channel and in the continental shelf, and thereby it couples dynamically the onshore and offshore systems. An additional novelty is that we compute the suspended sediment concentration inside the tidal channel and during the flood-phase in the offshore region through a one dimensional advection-diffusion equation that makes the sediment response lags with respect to the flow through scour and settling lags (Postma, 1967).

We use a quasi two-dimensional numerical model that resolves the fully nonlinear unsteady shallow water, sediment bed load transport and suspended sediment advection-diffusion equations along with the Exner equation for the bathymetric changes. We restrict our attention to the case of tide-dominated estuaries and neglect the effect of intertidal areas, gravitational circulations, Coriolis effect and river discharge, imposing a closed boundary at the landward end. Besides, the offshore ebb and flood phases in the continental shelf (offshore region) are analytically modeled through the integral-jet theory and through a conformal transformation of inviscid, plane and irrotational sink flow respectively.

In relation to the model, the following conclusions can be drawn:

- Starting from an arbitrarily imposed initial configuration, the model reproduces an asymptotic evolution of the system towards and equilibrium configuration marked by reduction of tidal asymmetries insides the channel. Such an equilibrium bed profile is characterized by a sediment front resulting from the scoured sediments at the seaward portion of the channel that generates a shoaling bed profile at the inner part of the channel. The plume dynamic mainly influence the outer part of the estuary: whereas the non-plume influence case attains a quasi-linear profile, the plume make the channel increase its concavity, reducing the final channel mouth depth.

- The plume is revealed as a key factor that speeds up the development of stable channel patterns: the timescale required to achieve quasi-equilibrium conditions is reduced when considering the dynamic coupling between offshore plume and tidal channel.

- The evolution of the tidal channel towards an equilibrium configuration also alters the plume dynamics: during the transient process the plume narrows, reduces its velocity, and decreases the concentration of the sediment load. As a consequence of these modifications, the depositional rates at the continental shelf drastically reduce.

\section{ACKNOWLEDGEMENTS}

This research was funded by the Spanish Ministry of Education through its postgraduate fellowship program (grant AP2012-05431).

\section{References}

P. Blondeaux, B. De Bernardinis, and G. Seminara. Correnti di marea in prossimità di imboccature e loroinfluenza sul ricambio lagunare. Atti del XVIII convegno di idraulica e costruzioni idrauliche, Bologna, pages 21-23, 1982.

M. Bolla Pittaluga, N. Tambroni, A. Canestrelli, R. Slingerland, S. Lanzoni, and G. Seminara. Where river and tide meet: The morphodynamic equilibrium of alluvial estuaries. Journal of Geophysical Research: Earth Surface, 120(1):75-94, 2015.

M. H. Chaudhry. Open-channel flow. Springer Science \& Business Media, 2007.

H. De Swart and J. Zimmerman. Morphodynamics of tidal inlet systems. Annual review of fluid mechanics, 41:203-229, 2009. 
S. Fagherazzi, D. A. Edmonds, W. Nardin, N. Leonardi, A. Canestrelli, F. Falcini, D. Jerolmack, G. Mariotti, J. C. Rowland, and R. L. Slingerland. Dynamics of river mouth deposits. Reviews of Geophysics, 53(3): 642-672, 2015.

A. Hibma, H. M. Schuttelaars, and Z. B. Wang. Comparison of longitudinal equilibrium profiles of estuaries in idealized and process-based models. Ocean Dynamics, 53(3):252-269, 2003.

A. M. Jiménez-Robles, M. Ortega-Sánchez, and M. Losada. Effects of basin bottom slope on jet hydrodynamics and river mouth bar formation. Journal of Geophysical Research: Earth Surface, 121:1110-1133, 2016.

P. B. Joshi. Hydromechanics of tidal jets. Journal of the Waterway Port Coastal and Ocean Division, 108 (3):239-253, 1982.

S. Lanzoni and G. Seminara. On tide propagation in convergent estuaries. Journal of Geophysical Research, 103:30-793, 1998.

S. Lanzoni and G. Seminara. Long-term evolution and morphodynamic equilibrium of tidal channels. Journal of Geophysical Research: Oceans, 107(C13001), 2002.

N. Leonardi, A. Canestrelli, T. Sun, and S. Fagherazzi. Effect of tides on mouth bar morphology and hydrodynamics. Journal of Geophysical Research: Oceans, 118(9):4169-4183, 2013.

N. Leonardi, T. Sun, and S. Fagherazzi. Modeling tidal bedding in distributary-mouth bars. Journal of Sedimentary Research, 84(6):499-512, 2014.

E. Meyer-Peter and R. Müller. Formulas for bed-load transport. In Proceedings of the 2nd Meeting of the International Association for Hydraulic Structures Research, pages 39-64. International Association of Hydraulic Research Delft, 1948.

M. Ortega-Sánchez, M. Losada, and A. Baquerizo. On the development of large-scale cuspate features on a semi-reflective beach: Carchuna beach, Southern Spain. Marine Geology, 198(3):209-223, 2003.

M. Ortega-Sánchez, M. A. Losada, and A. Baquerizo. A global model of a tidal jet including the effects of friction and bottom slope. Journal of Hydraulic Research, 46(1):80-86, 2008.

E. Özsoy. Ebb-tidal jets: a model of suspended sediment and mass transport at tidal inlets. Estuarine, Coastal and Shelf Science, 22(1):45-62, 1986.

E. Özsoy and Ü. Ünlüata. Ebb-tidal flow characteristics near inlets. Estuarine, Coastal and Shelf Science, $14: 251-263,1982$.

C. Paola and V. Voller. A generalized exner equation for sediment mass balance. Journal of Geophysical Research: Earth Surface, 110(F04014), 2005.

H. Postma. Sediment transport and sedimentation in the estuarine environment. Estuaries. AAAS, 83: 158-179, 1967.

D. Prandle. Relationships between tidal dynamics and bathymetry in strongly convergent estuaries. Journal of Physical Oceanography, 33(12):2738-2750, 2003.

N. Rajaratnam. Turbulent jets. Elsevier, 1976.

H. Schuttelaars and H. d. Swart. An idealized long-term morphodynamic model of a tidal embayment. European Journal of Mechanics - B/Fluids, 15:55-80, 1996.

H. Schuttelaars and H. d. Swart. Multiple morphodynamic equilibria in tidal embayments. Journal of Geophysical Research: Oceans, 105(C10):24105-24118, 2000.

G. Seminara, S. Lanzoni, N. Tambroni, and M. Toffolon. How long are tidal channels? Journal of Fluid Mechanics, 643:479-494, 2010. 
R. Soulsby. Dynamics of marine sands: a manual for practical applications. Thomas Telford, 1997.

H. M. Stommel and H. G. Former. On the nature of estuarine circulation: part i (chapters 3 and 4 ). Technical report, Woods Hole Oceanographic Institution, 1952.

N. Tambroni and G. Seminara. Are inlets responsible for the morphological degradation of venice lagoon? Journal of Geophysical Research: Earth Surface, 111(F3), 2006.

N. Tambroni, M. Bolla Pittaluga, and G. Seminara. Laboratory observations of the morphodynamic evolution of tidal channels and tidal inlets. Journal of Geophysical Research: Earth Surface, 110(F4), 2005.

I. Todeschini, M. Toffolon, and M. Tubino. Long-term morphological evolution of funnel-shape tidedominated estuaries. Journal of Geophysical Research: Oceans, 113(C5), 2008.

H. R. Vallentine. Applied hydrodynamics. Springer, 2013.

L. C. van Rijn. Sediment transport, part II: Suspended load transport. Journal of Hydraulic Engineering, 110(11):1613-1641, 1984a.

L. C. van Rijn. Sediment pick-up functions. Journal of Hydraulic Engineering, 110(10):1494-1502, 1984 b.

L. C. van Rijn. Principles of sediment transport in rivers, estuaries and coastal seas, volume 1006. Aqua publications Amsterdam, 1993.

F. C. Wang. The dynamics of a river-bay-delta system. Journal of Geophysical Research: Oceans, 89(C5): 8054-8060, 1984.

J. Winterwerp. On the sedimentation rate of cohesive sediment. Proceedings in Marine Science, 8:209-226, 2007.

L. Wright. Sediment transport and deposition at river mouths: a synthesis. Geological Society of America Bulletin, 88(6):857-868, 1977.

Q. Yu, Y. Wang, S. Gao, and B. Flemming. Modeling the formation of a sand bar within a large funnelshaped, tide-dominated estuary: Qiantangjiang estuary, china. Marine Geology, 299:63-76, 2012.

Z. Zhou, G. Coco, I. Townend, M. Olabarrieta, M. van der Wegen, Z. Gong, A. D’Alpaos, S. Gao, B. E. Jaffe, G. Gelfenbaum, et al. Is "morphodynamic equilibrium" an oxymoron? Earth-Science Reviews, 2016. 